\title{
The Experience of Competitive Mesocycle Organization in Junior Mini-Golf
}

\author{
Korolkov A.N. \\ Moscow State Pedagogical University \\ Moscow, Russia \\ Strizhak A.P. \\ Moscow State Pedagogical University \\ Moscow, Russia
}

\author{
Lysov E.A. \\ Moscow State Pedagogical University \\ Moscow, Russia \\ Tarasova L.V. \\ Federal Scientific Center All-Russian Scientific Research \\ Institute of Physical Culture \\ Moscow, Russia
}

\begin{abstract}
The article considers the aspects of competitive mesocycle organization in junior mini-golf. On the basis of the results of statistical observations over junior athletes during competitive seasons 2018-19 we defined an effective content of competitive mesocycle, which includes 6-7 weekly supplying competitions. It was proved that the effectiveness of competitive mesocycle organization with 6-7 weekly supplying competitions is $\mathbf{7 0 - 8 0 \%}$ during pedagogically important sports results increase.
\end{abstract}

Keywords-peak of sports fitness; competitive readiness; adaptation; super-compensation; athletes; mini-golf; mesocycle.

\section{INTRODUCTION}

Peak of fitness achievement for the main start of the season is one of the main objectives of sports training. Depending on the amount of the main competitions in the season this objective is solved by means of pre-competitive micro-cycles of different content alternation $[1,3,5,6]$. One of necessary conditions for the peak of fitness achievement is the number of supplying competitions [4].

\section{LITERATURE REVIEW}

In the work by S.E. Pavlov [5] it is stated that the peak of sports fitness in swimming is achieved during the 6-7th week of the competitive mesocycle. In the work by A.V. Voronkov [2] it is stated that the most effective interval between the competitions is 1,5 or 2 weeks. In jumping kinds of athletics the stage of sports fitness development for the main start is 4-6 weeks, 2 control competitions and 2-3 competitions with a high level of competitiveness [7, 8, 9].

Thus, the duration of sports fitness development for the main start in cyclic kinds is within the limits of 6-10 weeks, in speed-power $-4-8$ weeks.

In junior mini-golf season includes two peaks: an athlete should achieve the peak of fitness twice. First for the Championship of Russia, which is the main and qualifying start for junior national team formation and is held at the end of June, and secondly for the International competition (Championship of Russia or World Championship among juniors, which is held at the beginning of August). Till now the Championship of Russia was held during the first decade of May and young athletes didn't have enough time to prepare for it, as they didn't have the opportunity to train outside on the grounds covered with snow. As a result, the athletes, first of all, didn't achieve the peak of fitness by the time of the Championship of Russia beginning, and secondly, because of a long-term break between the main starts, lost their sports readiness by the time of the International competition.

The effectiveness substantiation of competitive mesocycle organization, which includes 6 supplying weekly competitions for the peak of fitness achievement by the time of main starts beginning.

\section{RESEARCH Methodology}

During the research we considered the statistical data concerning the effectiveness of the game at the Championship of Russia in 2018 and 2019. The athletes of the control and the experimental groups took part in the supplying starts every week at the stages of the Cup, Championship and the Championship of Samara region and also in the Championship of Moscow in mini-golf.

Comparative characteristic of the received results was realized by statistical methods using the package of complex analysis programs Stadia8.0/prof. In general 1710 initial results were handled.

\section{RESULTS}

Table 1 presents the results about the amount of supplying competitions (played rounds), the results of the $1^{\text {st }}$ and the main competition in the competitive mesocycle. As it is seen from the results, presented in this table, the results of 8 from 11 athletes improved, the results of one athlete almost didn't change and the results of two athletes became worse. Thus, the effectiveness of the used methodology is almost $73 \%$. At the same time, the average amount of the supplying starts in the studied sampling of athletes was 7 and the average amount of the played rounds was 32 .

The medians of the results comparison of the 1st and the main starts in the studied sampling using the criteria of the signs for the pair results $(\mathrm{p}=0,05)$ helps to set the validity of the hypothesis: "There are differences between the medians of 
the sampling", which proves statistically considerable increase in sports results.

TABLE I. PARAMETERS OF COMPETITIVE MESOCYCLE AND THE RESULTS OF THE FIRST AND THE MAIN START

\begin{tabular}{|c|c|c|c|c|c|}
\hline $\begin{array}{c}\text { №№ } \\
\text { athletes }\end{array}$ & $\begin{array}{c}\text { Number } \\
\text { of starts }\end{array}$ & $\begin{array}{c}\text { Number } \\
\text { of rounds }\end{array}$ & $\begin{array}{c}\text { Result } \\
1^{\text {st }} \text { start }\end{array}$ & $\begin{array}{c}\text { Result } \\
\text { the main } \\
\text { start }\end{array}$ & Difference \\
\hline 1 & 9 & 42 & 23,38 & 24,33 & $-0,95$ \\
\hline 2 & 8 & 38 & 25,75 & 23,75 & 2,00 \\
\hline 3 & 8 & 38 & 24,50 & 25,42 & $-0,92$ \\
\hline 4 & 8 & 38 & 26,38 & 25,83 & 0,55 \\
\hline 5 & 7 & 34 & 24,75 & 22,75 & 2,00 \\
\hline 6 & 7 & 34 & 24,50 & 24,67 & $-0,17$ \\
\hline 7 & 7 & 34 & 28,12 & 27,25 & 0,87 \\
\hline 8 & 7 & 34 & 26,63 & 25,67 & 0,96 \\
\hline 9 & 6 & 30 & 33,00 & 30,70 & 2,30 \\
\hline 10 & 4 & 22 & 25,00 & 24,00 & 1,00 \\
\hline 11 & 3 & 12 & 29,88 & 26,50 & 3,38 \\
\hline
\end{tabular}

Typical kind of sports results change depending on the number of the start is presented in picture 1 . It means that in the $1^{\text {st }}$ and the $3^{\text {rd }}$ start of the competitive season $12 \%$ of the respondents had high results within the range 22,7-24,4 strikes in a round, in the $6^{\text {th }}$ start of the competitive mesocycle the number of such athletes was $38 \%$.

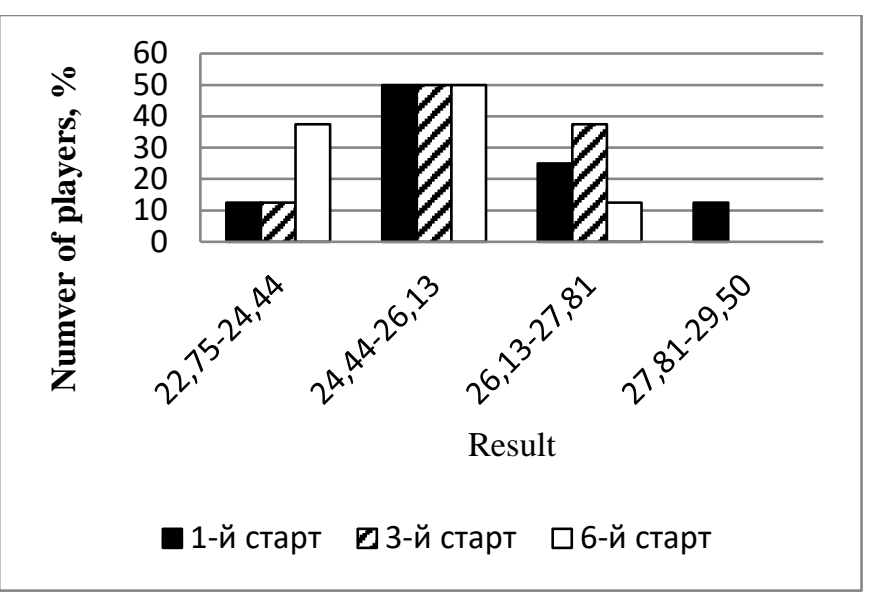

Fig. 1. The dynamics of sports results depending on the number of start

Table 2 presents the average results of the respondents from CG and EG, showed by them during the Championship of Russia in 2018 and 2019.

TABLE II. THE RESULTS COMPARISON OF THE CONTROL AND THE EXPERIMENTAL GROUPS IN 2018 AND 2019 ARE PRESENTED IN TABLE II

\begin{tabular}{|c|c|c|c|c|c|c|c|}
\hline \multirow{2}{*}{ № } & \multicolumn{3}{|c|}{ CG } & \multirow{2}{*}{ № } & \multicolumn{3}{|c|}{ EG } \\
\hline & 2018 & 2019 & $\begin{array}{l}\text { Differenc } \\
\mathrm{e}\end{array}$ & & 2018 & 2019 & $\begin{array}{l}\text { Differenc } \\
\mathrm{e}\end{array}$ \\
\hline 1 & 26,3 & 24 & $-2,3$ & 1 & 25,8 & 22,8 & -3 \\
\hline 2 & 29,6 & 26,8 & $-2,8$ & 2 & 28 & 24,3 & $-3,7$ \\
\hline 3 & 28,7 & 30,7 & 2 & 3 & 25 & 24,7 & $-0,3$ \\
\hline 4 & 31,7 & 26,5 & $-5,2$ & 4 & 26,4 & 27,8 & 1,4 \\
\hline 5 & 37,3 & 28,4 & $-8,9$ & 5 & 24,9 & 23,8 & $-1,1$ \\
\hline 6 & 23,8 & 22,8 & -1 & 6 & 25,7 & 25,4 & $-0,3$ \\
\hline
\end{tabular}

\begin{tabular}{|c|c|c|c|c|c|c|c|}
\hline 7 & 25,8 & 24,5 & $-1,3$ & 7 & 26,9 & 25,7 & $-1,2$ \\
\hline 8 & 25,1 & 25,4 & 0,3 & 8 & 42,5 & 37 & $-5,5$ \\
\hline 9 & 26,3 & 31,3 & 5 & 9 & 31,7 & 25,8 & $-5,9$ \\
\hline 10 & 28,8 & 25,5 & $-3,3$ & 10 & 29,5 & 24,6 & $-4,9$ \\
\hline $\begin{array}{c}\text { Averag } \\
\text { e }\end{array}$ & $\begin{array}{c}28,3 \\
4\end{array}$ & $\begin{array}{c}26,5 \\
9\end{array}$ & $-1,75$ & $\begin{array}{c}\text { Averag } \\
\text { e }\end{array}$ & $\begin{array}{c}28,6 \\
4\end{array}$ & $\begin{array}{c}26,1 \\
9\end{array}$ & $-2,45$ \\
\hline
\end{tabular}

Regardless of the fact that with the help of Student t-test we defined the validity of the hypothesis: "there are no differences between the sampling average differences of the results of 2018 and 2019 in the CG and the EG" in terms of statistical validity $\mathrm{p}=0,3$ it is obvious that the results in $\mathrm{CG}$ increased only among 7 from 10 athletes, in the EG the results improved among 9 athletes. Moreover, the average results increase in CG was 1,75 strikes in a round, in the EG- 2,45 strikes. Thus, regardless of statistically valid differences absence in the average results of CG and EG, the received real results increases in EG are pedagogically significant, both according to the frequency of their appearance in a sampling and according to an absolute volume.

\section{CONCLUSION}

As a result of the held research it was stated that the effectiveness of the used methodology was $73 \%$. At the same time, the average amount of the supplying starts in the studied sampling of athletes was 7 and the average amount of the played rounds was 32 .

The indirect verification of competitive mesocycle effectiveness with the series of weekly supplying competitions is a successful performance of junior national team at the Championship of Europe 2019 (Liepaja, Latvia). During this competition, for the first time in the history of Russian minigolf, three prizes were taken in a team competition and two silver medals were taken in individual competitions.

\section{References}

[1] Baykovskiy Yu.V. Methodology of competitive alpinists training mesocycle formation during "Alpine" and "Himalayn" styles of climbing use. Theory and practice of the applied and extreme kinds of sport. 2010, 2 (17), pp. 1-7.

[2] Voronkov A.V., Belyaev I.S., Dorokhin A. Yu., Kandabar A.N. Methodology of sports training of highly-qualifies weightlifters. Modern problems of science and education. 2017, 5, pp. 272.

[3] Nikitushkin V.G. Theory and methodology of junior sport. Moscow: Physical culture. 2010, 203.

[4] Pavlov S.E., Pavlova T.N., Davydov A.P., Pavlov A.S., Petrov A.A. Theoretical and methodical basis of modern technology of training qualified athletes. Fundamental research works. 2014, 8-3, pp. 722-727.

[5] Platonov V.N. Theory and periodization of sports training during the year: history of the question, state, discussions, ways of modernization. Theory and practice of physical culture. 2009, 9, pp. 18-34.

[6] Sabirova I.A. Training control of shooters: monograph. Voronezh: Scientific book. 2014, 177.

[7] Strizhak A.P., Zagorulko E.P. High jump: monograph. Academy of health. 2015, 88.

[8] Erkabulan Islyamov, Zinaida M. Kuznetsova. The most popular national sports and games of the Republic of Kazakhstan. The Russian Journal of Physical Education and Sport. 2019, 14(1), pp. 114-121. DOI: 10.14526/2070-4798-2019-14-1-132-140.

[9] Strizhak A.P. Sports training: realia and aspects. Theory and practice of physical culture. 2018, 3, pp. 57-60. 